\title{
Demand-Driven Acquisition at HKUST Library: the New Normal
}

\author{
Catherine S Y Kwok, Diana L. H. Chan, Ada S. M Cheung and Wong Ming Kan \\ Hong Kong University of Science and Technology Library
}

\section{Structured Abstract}

\section{Purpose}

This paper aims to evaluate the impact of three concurrent demand-driven acquisition programs on ebook collection development at HKUST Library.

\section{Design/methodology/approach}

COUNTER BR2 reports of the Ebrary, Wiley and JSTOR were analysed from the launch date of the respective program to June 30, 2014.

\section{Findings}

The value of two local demand-driven acquisition programs, Ebrary and Wiley, were seen. JSTOR program needs to be evaluated at local and consortial levels when the pilot is finished.

\section{Originality/value}

The experience of HKUST Library will provide a reference point for libraries who are yet to implement their DDA program.

\section{Keywords}

Ebooks, Demand-driven acquisitions, Patron-driven acquisitions, Collection development, Ebrary, JSTOR, Wiley, Usage, DDA, PDA

\section{Article Classification}

Case study

\section{Demand-Driven Acquisition}

Ebook collection development in Hong Kong academic libraries started in the early 2000's. Back then, to build a critical mass of ebooks, libraries purchased huge collections of ebooks or smaller subject collections based on projected user needs and institutional research profile. This traditional "just-in-case" collection was also supplemented by subscription and pick-andchoose ebooks.

In the past few years, a new wave of ebook acquisition, the demand-driven acquisition (DDA) or patron-driven acquisition (PDA) approach, has transformed the ebook landscape. Under DDA, the act of purchase no longer rests with the selector librarian, but with an unknowing user who discovers and triggers a purchase when the usage of a title exceeds a pre-determined threshold. A carefully executed DDA program will involve libraries working with publishers 
or ebook aggregators to define the content scope of the program, an agreement on the purchase definition, a pledged expenditure level, and the feeding of a large number of discovery records into the libraries' catalogs and their maintenance. DDA is an attractive model. Users are exposed to a large quantity of ebook titles, a scale unthinkable under the conventional "just-incase" mode. Libraries can choose to extend or cease the program based on budget available, and eventually purchase and own the titles that have received usage.

Below is a case study sharing the experiences of ebook acquisition before and after the implementation of three DDA pilot programs at the Hong Kong University of Science and Technology (HKUST) Library. Ebook usage before and after DDA programs will also be discussed.

\section{Collection Development of Ebooks at HKUST Library}

Founded in 1991, the HKUST Library has a collection of 716,000 print volumes, 260,000 ebooks, 43,000 periodical titles, 260 databases and 39,000 media items. Its user population comprises 8,800 undergraduates, 4,200 graduate students and 600 faculty members. As a young and dynamic university, HKUST was ranked first in 2013 QS University Rankings under the category Top 50 Under 50. The Library supports the teaching and research needs of four Schools-- Science, Engineering, Business and Management, Humanities and Social Science and various research centers and institutes at the University.

Ebooks currently represent $31 \%$ of all book titles held by the Library. The 2013 expenditures on ebooks amounted to $63 \%$ of the Library's total book spending and accounted for $12 \%$ of the Library's overall collection budget. A survey on U. S. academic libraries in 2011 revealed that on average ebook expenditures consumed $8.7 \%$ of their overall acquisitions budgets, and that each library held an average of 65,000 ebook titles. Respondents also indicated that these figures were expected to increase in the next few years (Ebooks, the new normal, 2011). HKUST Library, like many libraries worldwide, is accelerating the format shift from print books to ebooks.

The Library has an active print approval plan with YBP, who has been its chief supplier of western books since 1991. The ebook scenario is more complex. There are three approaches to ebook acquisition: subscription, individual purchase and consortial purchase. To ensure timeliness of content, subscription model is adopted for technology-related and engineering subjects. Safari, Books 24x7, ENGnetBase and Knovel, which the Library subscribes to, belong to this category. A fair proportion of the ebooks budget is allocated to outright purchase with perpetual ownership. The Library purchases directly from publishers such as Springer, Palgrave, Taylor \& Francis, and Morgan \& Claypool. Purchase decisions usually hinge on past usage, unit cost, subject balance or Digital Rights Management (DRM). Purchase level varies from full collection, subject collection to pick-and-choose. By far, the most cost-effective way is to acquire ebooks in bulk via consortia. There have been successive rounds of consortial purchases among the eight government-funded academic (JULAC) libraries in Hong Kong. Cumulatively, each member library has shared access and joint ownership to over 60,000 English titles. 


\section{Usage Trends of Ebooks, Ejournals and Print Books Before DDA}

The size of HKUST Library ebook collection has been relatively small when compared to other JULAC libraries in Hong Kong. As a research-intensive university, a large proportion of the Library's collection budget is reserved for maintaining ejournal subscriptions. Yet a comparison of the growth rate of ebook and ejournals from 2009 to 2012 and their respective usage reveals interesting findings. Ebooks not only outpaced ejournal growth rate by $13 \%$ over the three-year period, usage of ebooks also doubled itself from 144,200 Book Report 2 (BR2) downloads in 2009 to 288,900 in 2012, whereas the number of Journal Report 1 (JR1) downloads only increased by 50\%, from 895,000 in 2009 to 1,345,000 in 2012 .

Contrasted sharply with the surge in ebook downloads was the significant contraction of print book checkouts by $22 \%$. HKUST is certainly not alone in witnessing this phenomenon. Association of Research Libraries (ARL) and Council of Australian University Librarians (CAUL) statistics as well as JULAC statistics in Hong Kong all reveal the same trend. The total loans average in JULAC libraries decreased 25\% from 2009 to 2012, while CAUL registered a drop of $23 \%$ in the same period and ARL, a negative $11 \%$ from 2009 to 2011 (Association of Research Libraries, 2010-2012) (Council of Australian University Librarians, 2014) (Joint University Librarians Advisory Committee, 2013).

The above trend coincides with two recent survey findings in the U.S. Three in ten adults reported having read an ebook in 2013 (Pew Research Center, 2014). In an earlier survey, respondents said they preferred ebooks to print books when they wanted portability and convenient access (Pew Research Center, 2012).

\section{DDA as Timely Solution to Curriculum Change}

The Library closely monitored developments in DDA locally and abroad. The year 2012 was an opportune time to introduce DDA at HKUST. The university system in Hong Kong started to migrate from a three-year undergraduate system to a four-year one from fall 2012, resulting in an increase of student population by $23 \%$ for HKUST. In tandem with this major transition was a reformulated curriculum with a full range of general education, minor and interdisciplinary programs. Instead of buying books in the "just in case" mode, the Library saw DDA as a possible solution to meet the diversified curricular needs of a much expanded student population. The overriding goals of such a program were to expose users to a large number of discovery ebook titles and to purchase the high-used ones. It would be an alternative mode of ebook acquisition, whereby Library users would unknowingly take part.

\section{EBRARY DDA via YBP}

After careful evaluation of the DDA alternatives, the Library elected to work with Ebrary via YBP. MyiLibrary, EBL and EbscoHost were not chosen due to a mixture of reasons. In terms of DRM, EBL's loan day feature was indeed a stumbling block. The Library was mindful of the hassle and cost implication when a title's loan days were exhausted. As for purchase trigger 
definition, EBL's 5-minute free use compared less favorably with 10-minute free use of its competitors. EbscoHost was relatively new to DDA market in 2012 and its pricing was the least attractive.

Between Ebrary and MyiLibrary, the deciding factor was the former's partnership with YBP. YBP offered a suite of services that helped libraries implement their pilot DDA programs. Their holdings de-duplication service was unique, and addressed the Library's deep concern for buying the same title twice. Ebrary via YBP was a budget-conscious option too. Print book budget reserved for YBP was diverted to DDA spending. No extra funding was required. To stretch the purchasing power, it was decided to limit to Ebrary SUPO, i.e., single user license only, and to cap the price per title to US\$250. Standard trigger definition was employed: view 10 pages or 10-minute active use or any export (copy or print or download) function.

The Ebrary DDA pilot was launched without fanfare in October 2012 with over 12,000 discovery records added to the Library Catalog. Only titles published in 2011 or thereafter were included. This batch of seed records was mapped to the Library's YBP notification slips profile with detailed specifications on subject and non-subject parameters. Before Ebrary DDA, subject librarians had to select title by title via Gobi, the YBP online selection platform. They were relieved of their Gobi task when the pilot started. The program warmed up shortly after launch, and healthy usage traffic and purchase activities were observed.

As of June 2014, a total of 22,117 discovery records were loaded to the Library Catalog, of which 3,090 recorded usage. $1,689(7.6 \%)$ titles were used below the trigger threshold. Usage of 1,401 titles $(6.3 \%)$ reached the threshold and were triggered for purchase. To better understand the benefits of DDA, a review was made on top ten used publishers (Table 1). The top five used publishers in order were Wiley, top-tiered University Presses, Taylor \& Francis, CRC Press and Elsevier. $47 \%$ of all used titles came from these four commercial publishers and another $18 \%$ from various University Presses. The purchased over used titles ratios for the top five publishers varied from University Presses' 45\% to Wiley's 57\%. The ratios suggested that about half of the viewed titles were eventually purchased. It also meant users could browse a good number of non-purchased titles for free.

Wiley distinguished itself as the most used and purchased publisher. It accounted for $10 \%$ of the total number of discovery records, yet $24 \%$ of all purchased titles were Wiley imprints. The corresponding figures for Taylor \& Francis were $2 \%$ and $11 \%$, which were equally impressive. $18 \%$ of purchased titles were from various University Presses. Library users proved to be smart buyers and trustworthy partners in ebook acquisition. Triggered purchases were vetted and deemed to be good academic titles from reputable publishers matching HKUST's teaching and research programs.

\section{WILEY UBCM}

The strong presence of Wiley imprints in the initial months of the Ebrary DDA pilot provided an impetus for the Library to embark on a Wiley Usage-Based Collection Management (UBCM) program in May 2013. From negotiations of terms to implementation, it was a straightforward 
process. With an agreed prepaid amount, Wiley turned on access to all their complete online books, comprising nearly 15,000 titles. Library users immediately benefited from integrated access to a full catalog of ebooks and ejournals on the Wiley Online Library (WOL) platform. The pilot lasted for nine months with unexpectedly high traffic, especially during the initial three months.

The evidence-based approach seemed to work in harmony with Ebrary DDA. The Library determined what titles to buy and own at the end of the trial. Since purchase was librarianmediated instead of usage-triggered, there was a great deal of room for manipulation. First and foremost was no duplication with local holdings in either print or electronic format. Titles were sorted by usage, and top used titles mostly became confirmed purchases. Additional selection filters related to price and publication year. Preference was given to titles published in the recent three years and price per title was kept below US\$250. A small fraction of confirmed purchases was not usage-driven, though. There was a conscious decision to purchase titles in specific subject areas such as finance and accounting in view of their quality, good enough usage and moderate price.

Wiley UBCM proved to be a great success. Its usage went up in leaps and bounds, from less than 4,000 in 2012 to over 200,000 in 2013, a fiftyfold increase! A review of the high-used titles provided strong clues for current research interests. It was hardly surprising to see chemistry or materials science books among the top used. It was indeed surprising to see a bible commentary work and many clinical titles on the top used chart, given the small religion program and absence of medical school at HKUST. Of all the used titles from the pilot UBCM, $14 \%$ were published prior to 2001, 50\% were published between 2001 and 2010, and 36\% were current three-year titles. These $64 \%$ Wiley backlist titles were unique to UBCM as Ebrary DDA only covered current two-year frontlists. It was also observed that since UBCM, ejournal usage on Wiley Online Library had increased on average by 50\%. It led one to believe that UBCM had boosted the overall level of research activity on WOL, though it was hard to prove the causal relationship between the two. Convinced by the many-sided benefits of UBCM, the Library entered into a second round of UBCM from April 2014.

\section{Consortial JSTOR DDA}

The Library did not stop at its local DDA programs. By 2014, most of the eight JULAC libraries in Hong Kong had experience with their own DDA programs. There were heavy discussions on a consortial DDA program, whereby member libraries could collaborate on collection building and enjoy joint access and perpetual ownership of ebooks. The difficulty of such a program was to decide on a subject profile that could benefit all libraries. Reconciling the diverse teaching and research needs of all members was not easy. In the end, it was decided to focus just on humanities and social sciences subjects. It was also decided at the outset not to offer short term loans for cost control and to choose a platform with relatively lenient DRM.

The consortium elected to collaborate with JSTOR, a University Press aggregator. JSTOR was a good match with the pilot's DRM requirement and subject profile. After many rounds of negotiations, both parties were able to conclude on the list price multiplier, purchase trigger 
definitions and other details of the deal. In March 2014, the consortial JSTOR DDA pilot was launched with 3,200 DRM-free frontlist titles with periodic new title feeds. Given the popularity of University Presses under Ebrary DDA, the Library welcomed the experiment, but was concerned that JSTOR's predominant focus on history, geography and literature would not meet the local interests of HKUST.

How was the program received? From March to June, usage initiated by HKUST users was the lowest among all eight libraries. Its usage only accounted for less than $2 \%$ of the entire consortium traffic. Only 75 titles were used at least once out of the entire pool of discovery titles. The top used titles in the consortium recorded zero or single-digit usage by HKUST. This posed a sharp contrast to Ebrary DDA and Wiley UBCM, and could be attributed to a mismatch of JSTOR subject coverage and HKUST's research needs. The University's School of Humanities and Social Science is indeed the smallest among the four Schools in terms of student size and the scope of its undergraduate programs.

While usage at HKUST seemed discouraging, the quality of triggered titles was reassuringly high. The cost per title was very modest compared to Ebrary and Wiley. With such a short period of implementation, it is too early to draw a conclusion. More detailed study is needed to assess the benefits and shortcomings of the consortial DDA program.

\section{Post-DDA Ebook Landscape}

With three concurrent DDA programs, the HKUST Library has achieved its goal to boost its ebook collection. From 2012 to 2014, the ebook collection size increased sharply by $40 \%$. The overall ebook usage in 2013 topped a million downloads, which was 3.5 times higher than 2012 when there was no DDA. A logical extension was that Wiley and Ebrary became the second and third most-used ebook platforms in 2013, after SpringerLink. The per student FTE ebook download was raised to 85 in 2013 from 30 in 2012. This jump was all the more impressive in the light of the much expanded undergraduate population from fall 2012.

To understand the impact of DDA, the Library examined the usage of Ebrary and Wiley before and after DDA (Table 2). There were no JSTOR ebooks prior to the consortial pilot, hence there was no basis for comparison. The 2012 Ebrary figures reflect the usage of a collection of titles acquired via JULAC consortium and by pick-and-choose, contrasted against the Ebrary DDA usage from October 2012 to June 2014. Similarly, Wiley data before UBCM (2012) and after UBCM (January 2013 to June 2014) are given side by side. The Ebrary increase in BR2 download under DDA was in proportion to the number of title increase. Wiley UBCM provided 15 times more titles than before, yet its BR2 download dramatically increased by 54 times. The average number of downloads per used title improved under both Ebrary DDA (from 56 to 61) and Wiley UBCM (from 14 to 23). Ebrary's percentage of used titles with at least 50 downloads increased from $24 \%$ to $33 \%$ and Wiley from $4 \%$ to $6.7 \%$. Wiley's overall unused titles dropped significantly to $37 \%$ under UBCM. It was not the case for Ebrary DDA.

The discovery titles of the three DDA programs as of June 2014 were also analyzed by broad LC subject classifications (Figure 1). Ebrary covered a wide spectrum of subjects, except law, 
naval and military science. These exclusions were in accordance with the Library's YBP profile specifications. Wiley was overtly strong in Medicine, Science and Technology, and had decent coverage in Social Sciences. JSTOR had the greatest concentration of titles in History, Language and Literature, Philosophy, Psychology, Religion, and Social Sciences.

Usage peaked in Science, Technology, Medicine, and the Social Sciences under which the various accounting, business and finance subjects were grouped. This coincided with the intensity of HKUST's teaching and research in these areas. The relatively low used subject areas also invited close inspection. They perfectly illustrated the benefits of DDA. Look at Language and Literature, for instance. Out of a total of 5,555 discovery titles from all three platforms, $10 \%$ were used, and only 200 were singled out for purchases. User activities decided which top $3.6 \%$ used titles were worthy additions to the Library collection.

\section{Conclusion}

DDA has become the new normal at HKUST Library. The Library strategically uses DDA to supplement conventional modes of collection development. The conventional channels of book acquisition still prevail to ensure a distributed growth in all profiled subject areas. It is often argued that DDA meets immediate research needs, but the lifespan of purchased titles is short (Anderson, 2011). The Library has to perform more in-depth analysis to substantiate or invalidate this hypothesis.

The Library has launched three DDA programs in two years. The value of consortial JSTOR DDA remains to be seen. The local activity so far suggests that JSTOR DDA may not be an appropriate solution for HKUST. A more thorough assessment is required at both local and consortial levels. Data in favor of YBP/Ebrary and Wiley are solid. Wiley seems to offer the best solution in terms of ease of use, discoverability and subject relevance, yet it is an expensive solution. It can only be repeated subject to adequate funding. YBP/Ebrary is all-rounded in profiled subjects, diversity of imprints, and currency of titles. It is also the most sustainable of all three models, since the funding is diverted from print book expenditure. Its DRM is the least favored among the three, yet is not insurmountable. Face-to-face help points and online user guide are available. It is also reassuring to know that Ebrary allows the upgrade of license from SUPO (single user) to MUPO (multiple user) when needs arise. Ebrary DDA is approaching its second anniversary at HKUST. It has become a core component of the Library's ebook acquisition program.

The expansion of the HKUST Library's DDA program has been gradual, deliberate and exploratory. It is a combination of DDA approaches and partners: approval vendor coupled with a commercial aggregator, single publisher and finally a University Press aggregator. With experiences and data from these programs, the Library continues to juggle for the best formula to deliver ebook content at point of need. 


\section{References}

Anderson, R. (2011), "What patron-driven acquisition (PDA) does and doesn't mean; an FAQ", available at: http://scholarlykitchen.sspnet.org/2011/05/31/what-patron-drivenacquisition-pda-does-and-doesnt-mean-an-faq/ (accessed 19 September 2014).

Association of Research Libraries. (2010), ARL Statistics. 2009/10. Association of Research Libraries, Washington, D. C.

Association of Research Libraries. (2011), ARL Statistics. 2010/11. Association of Research Libraries, Washington, D. C.

Association of Research Libraries. (2012), ARL Statistics. 2011/12. Association of Research Libraries, Washington, D. C.

Council of Australian University Librarians. (2014), "CAUL Statistics-Details from Previous Years", available at: http://www.caul.edu.au/caul-programs/caul-statistics/previousyears (accessed 21 August 2014).

Ebooks, The New Normal : Ebook Penetration \& Use in U.S. Academic Libraries : Second Annual Survey. (2011), Library Journal, New York, NY.

Joint University Librarians Advisory Committee. (2013), "Joint University Librarians Advisory Committee Statistics, 2009/10 - 2012/13", available at: http://www.julac.org (accessed 19 September 2014).

Pew Research Center. (2012), "The rise of e-reading", available at: http://libraries.pewinternet.org/2012/04/04/the-rise-of-e-reading/ (accessed 19 September 2014).

Pew Research Center. (2014), "E-reading rises as device ownership jumps", available at: http://www.pewinternet.org/2014/01/16/e-reading-rises-as-device-ownership-jumps/ (accessed 19 September 2014).

\section{Further Readings}

Fischer, K. S., Wright, M., Clatanoff, K., Barton, H. and Shreeves, E. (2012), "Give 'em what they want: a one-year study of unmediated patron-driven acquisition of e-books", College \& Research Libraries, Vol. 73 No. 5, pp. 469-492.

National Information Standards Organization. (2014), "NISO RP-20-2014, Demand driven acquisition of monographs: a recommended practice of the National Information Standards Organization", available at: http://www.niso.org/workrooms/dda (accessed 19 September 2014). 
Table 1: Ebrary DDA Top Ten Used Publishers from October 2012 to June 2014

\begin{tabular}{|c|c|c|c|c|c|c|c|c|}
\hline PUBLISHER & $\begin{array}{l}\text { Total No. of } \\
\text { Discovery } \\
\text { Titles }\end{array}$ & $\begin{array}{l}\text { Total No. of } \\
\text { Purchased } \\
\text { Titles }\end{array}$ & $\begin{array}{l}\text { Total No. } \\
\text { of Titles } \\
\text { with Usage }\end{array}$ & $\begin{array}{l}\text { Total } \\
\text { BR2 } \\
\text { Usage }\end{array}$ & $\begin{array}{l}\% \text { of } \\
\text { Discovery } \\
\text { Titles \# }\end{array}$ & $\begin{array}{l}\% \text { of } \\
\text { Purchased } \\
\text { Titles }^{\wedge}\end{array}$ & $\begin{array}{l}\% \text { of } \\
\text { Purchased } \\
\text { Over Used } \\
\text { Titles }\end{array}$ & $\begin{array}{l}\text { Average } \\
\text { Use per } \\
\text { Publisher }\end{array}$ \\
\hline Wiley & 2,161 & 351 & 611 & 50,685 & $10 \%$ & $25 \%$ & $57 \%$ & 83 \\
\hline University Presses & 6,424 & 250 & 555 & 35,561 & $29 \%$ & $18 \%$ & $45 \%$ & 64 \\
\hline Taylor \& Francis & 507 & 161 & 358 & 20,268 & $2 \%$ & $11 \%$ & $45 \%$ & 57 \\
\hline CRC Press & 756 & 112 & 222 & 18,193 & $3 \%$ & $8 \%$ & $50 \%$ & 82 \\
\hline Elsevier & 816 & 113 & 246 & 14,833 & $4 \%$ & $8 \%$ & $46 \%$ & 60 \\
\hline World Scientific & 355 & 43 & 76 & 5,578 & $2 \%$ & $3 \%$ & $57 \%$ & 73 \\
\hline $\begin{array}{l}\text { Nova Science } \\
\text { Publishers }\end{array}$ & 1,135 & 64 & 169 & 5,377 & $5 \%$ & $5 \%$ & $38 \%$ & 32 \\
\hline Palgrave Macmillan & 1,163 & 38 & 83 & 4,705 & $5 \%$ & $3 \%$ & $46 \%$ & 57 \\
\hline De Gruyter & 210 & 15 & 25 & 3,128 & $1 \%$ & $1 \%$ & $60 \%$ & 125 \\
\hline Ashgate Publishing & 829 & 28 & 70 & 3,037 & $4 \%$ & $2 \%$ & $40 \%$ & 43 \\
\hline $\begin{array}{l}\text { Total of Top } 10 \\
\text { Publishers }\end{array}$ & 14,356 & 1,175 & 2,415 & 161,365 & $65 \%$ & $84 \%$ & $48 \%$ & 68 \\
\hline
\end{tabular}

\# \% of Discovery Titles = no. of publisher's discovery titles over total no. of discovery titles (i.e., 22,117) as of June 2014

$\wedge \%$ of Purchased Titles $=$ no. of publisher's purchased titles over total no. of purchased titles (i.e., 1,401) as of June 2014

Table 2: Usage of Ebrary and Wiley before and after DDA/UBCM

\begin{tabular}{|c|c|c|c|c|}
\hline Ebook Platform & $\begin{array}{l}\text { Ebrary } \\
\text { Perpetual } \\
2012\end{array}$ & $\begin{array}{l}\text { Ebrary DDA } \\
\text { Oct } 2012 \text { to } \\
\text { June } 2014\end{array}$ & $\begin{array}{l}\text { Wiley } \\
\text { Perpetual } \\
2012\end{array}$ & $\begin{array}{l}\text { Wiley UBCM } \\
\text { Jan } 2013 \text { to June } \\
2014\end{array}$ \\
\hline No. of Titles & 5,081 & 22,117 & 1,013 & 14,970 \\
\hline BR2 Downloads & 54,625 & 186,966 & 3,945 & 214,704 \\
\hline $\begin{array}{l}\% \text { of Used Titles with } 50 \\
\text { Downloads or More }\end{array}$ & $24 \%$ & $33 \%$ & $4 \%$ & $6.7 \%$ \\
\hline $\begin{array}{l}\text { Average No. of } \\
\text { Downloads Per Used } \\
\text { Title }\end{array}$ & 56 & 61 & 14 & 23 \\
\hline$\%$ of Unused Titles & $81 \%$ & $86 \%$ & $73 \%$ & $37 \%$ \\
\hline
\end{tabular}


Figure 1

Subject Analysis of 3 DDA Models

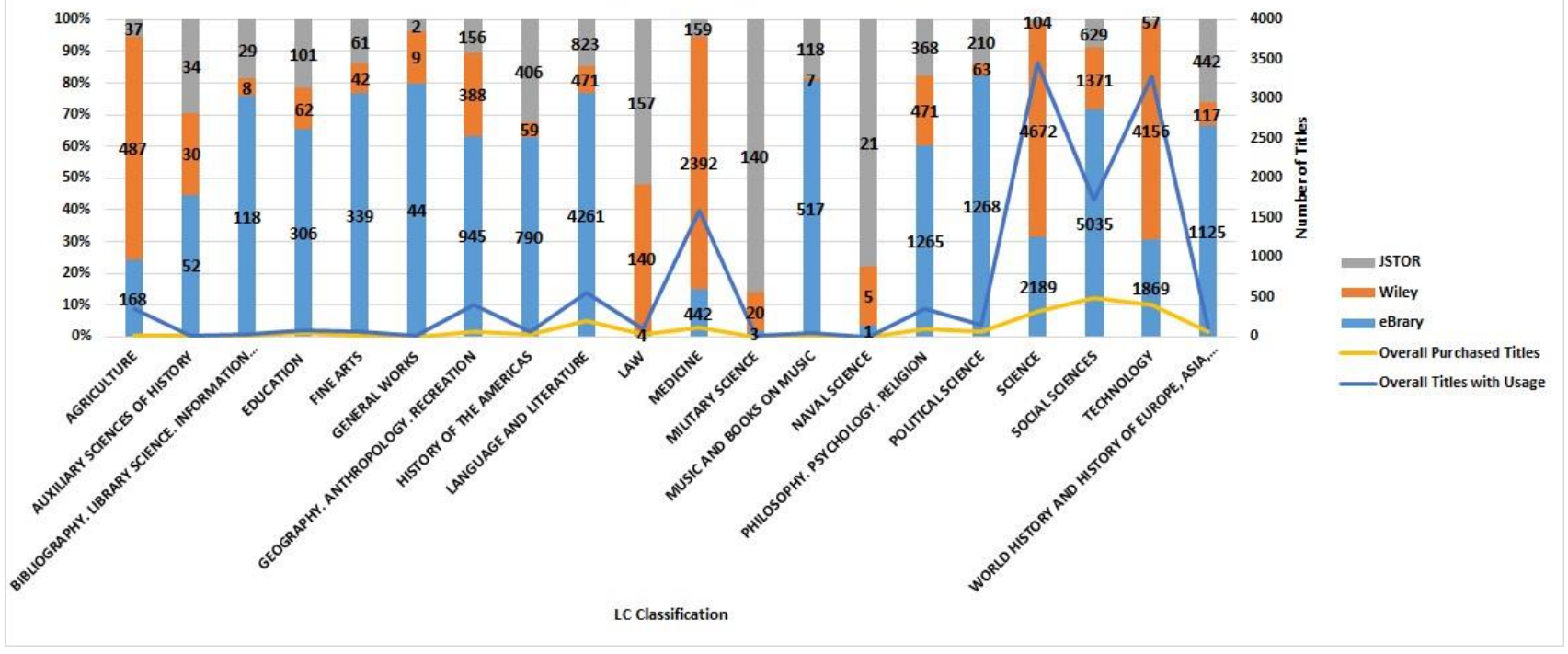

